\title{
Hormonal Regulation of Calcium Signaling in Endocrine Cancers
}

\author{
${ }^{1}$ Nelson George, ${ }^{2}$ Megha Changtoo, ${ }^{3}$ Aru Singh, ${ }^{4}$ Praveen Kumar, ${ }^{5}$ Srinivasan Muthuswamy, ${ }^{6}$ Bandana Chakraborthy
}

\begin{abstract}
The calcium ion $\left(\mathrm{Ca}^{2+}\right)$ plays a fundamental role in a number of physiological functions including bone formation, muscle contraction, secretion, enzyme cofactor, stabilization of membrane potentials, blood coagulation, etc. Calcium is homeostatically regulated by hormones that determines calcium balance within the body. The hormones PTH, 1,25-(OH)2D3 and calcitonin are altered in endocrine cancers which are in turn regulated by calcium. The main focus of this review is how hormones can regulate calcium homeostasis in endocrine cancers.
\end{abstract}

Keywords: Endocrine cancers, Calcium homeostasis, Hormones PTH, 1,25-(OH) 2D3 and calcitonin.

How to cite this article: George N, Changtoo M, Singh A, Kumar P, Muthuswamy S, Chakraborthy B. Hormonal Regulation of Calcium Signaling in Endocrine Cancers. World J Endoc Surg 2014;6(2):77-80

Source of support: Nil

Conflict of interest: None

\section{INTRODUCTION}

\section{Importance of Calcium in Biological System}

Calcium $\left(\mathrm{Ca}^{2+}\right)$ is a useful ubiquitous ion in biology. It has an oxidation state of +2 which gives greater strength in interacting with anionic complexes compared to sodium, potassium or other monocations. $\mathrm{Ca}^{2+}$ is the fifth most abundant element in the body but $99 \%$ of it is sequestered in bone. Among the roles for $\mathrm{Ca}^{2+}$, a major role is acting as a secondary signal to convert signals from the extracellular environment into specific intracellular responses. Also, $\mathrm{Ca}^{2+}$ is involved in the rapid depolarization of cells in neurons and muscle cells. These actions need to be tightly controlled. Therefore, $\mathrm{Ca}^{2+}$ is kept at low levels in the cell's cytosol

\footnotetext{
${ }^{1-5}$ PhD Student, ${ }^{6}$ Scientist

${ }^{1}$ Department of Endocrine Surgery, Sanjay Gandhi, Postgraduate Institute of Medical Sciences, Lucknow, Uttar Pradesh, India

2-4,6 Department of Molecular Medicine and Biotechnology Sanjay Gandhi Postgraduate Institute of Medical Sciences Lucknow, Uttar Pradesh, India

${ }^{5}$ Department of Genetics, Sanjay Gandhi Postgraduate Institute of Medical Sciences, Lucknow, Uttar Pradesh, India

Corresponding Author: Nelson George, PhD Student Department of Endocrine Surgery, Sanjay Gandhi Postgraduate Institute of Medical Sciences, Lucknow, Uttar Pradesh, India e-mail: nelsongeorge141@gmail.com
}

until needed. $\mathrm{Ca}^{2+}$ is stored in the endoplasmic reticulum (ER) and mitochondria for quick release that initiates $\mathrm{Ca}^{2+}$ dependent actions. ${ }^{1}$ Calcium ions play vital roles in a variety of important physiological functions of the cell, including control of cell cycle progression, cell differentiation, mitosis, apoptosis, ETosis, cell mobility, macrophage activation, chromatin packaging and modifications, protein folding and control of potassium and calcium channels. Often $\mathrm{Ca}^{2+}$ is serving as a secondary messenger. ${ }^{2}$ Calcium interacts with cyclic AMP, NO, phosphatidylinositol-3-OH kinase, feedback interactions and mitogen-activated protein kinase in different signaling pathways.

\section{Major Hormones which take Part in Calcium Homeostasis}

In endocrine cancers, the major hormones which are altered mainly include PTH, 1,25-(OH)2D3 and calcitonin. The extracellular fluid (or plasma) calcium concentration is tightly controlled by a complex homeostatic mechanism involving fluxes of calcium between the extracellular fluid (ECF) and the kidney, bone, and gut. These fluxes are carefully regulated by three major hormones: parathyroid hormone (PTH), calcitonin, and 1,25-dihydroxyvitamin D[1,25(OH)2D3]. Important cellular functions are dependent on the maintenance of the extracellular calcium concentration within a narrow range. ${ }^{3}$ Since, these enzymes play a major part in the calcium homeostasis, it is important to give a crosstalk on the alterations in calcium homeostasis of these hormones due to occurrence endocrine cancers.'

\section{Role of Calcium through Hormonal Regulation in Different Endocrine Cancers}

The major endocrine cancers in which the calcium signaling is altered by the hormonal regulation are prostate cancer, parathyroid cancer and breast cancer. Cancer that forms in tissues of the prostate (a gland in the male reproductive system found below the bladder and in front of the rectum). Prostate cancer usually occurs in older men. Parathyroid cancer is a rare cancer that forms in tissues of one or more of the parathyroid glands (four pea-sized glands in the neck that make parathyroid hormone, which helps the body store and use calcium). The most common type of breast cancer is ductal carcinoma, which begins in the lining of the milk ducts 
(thin tubes that carry milk from the lobules of the breast to the nipple). Another type of breast cancer is lobular carcinoma, which begins in the lobules (milk glands) of the breast.

In prostate cancer, PTH plays a mitogen role through alterations in calcium homeostasis. There are several studies on breast cancer and prostate cancer with its relation to PTH and $1,25(\mathrm{OH}) 2 \mathrm{D}$. In most of other endocrine cancers the changes in calcium homeostasis with respect to PTH, 1,25(OH)2D and calcitonin is well studied. The main focus of this review is how hormones can regulate calcium homeostasis in endocrine cancers.

\section{Role of PTH-dependent Calcium Homeostasis in Different Endocrine Cancer}

In 1962, Ludwig observed that metastases from prostate cancer cause increased serum levels of PTH. However, the epidemiologic and clinical implications of that observation have been little appreciated, PTH is now understood to be a mitogen for prostate cancer cells. ${ }^{4}$ In case of prostate cancer serum, PTH levels are very high and it promotes the progression of prostate cancer in bones. There are several studies on the role of PTH on CaR modulations in $\mathrm{Ca}^{2+}$ homeostasis. Some studies show increased bone turnover produced by PTH helps to increase prostate cancer metastasis to bone ${ }^{5}$ and the bone re-absorption induced by the dietary deficiency of calcium leads to the bony metastasis. The PTHrP is believed to be a mediator for $70 \%$ of breast and prostate cancer: (1) higher PTHrP expression in prostatic dysplasia (prostate intraepithelial neoplasia) than in normal prostate epithelium and (2) higher PTHrP expression in prostate carcinoma than in benign hyperplasia suggests that there are promalignant or proliferative effects of PTHrP that participate in the pathophysiology of prostate cancer. ${ }^{6-8}$

In normal breast cells, similarly to PTH release, the secretion of PTHrP is inhibited by increase in the $\mathrm{Ca}^{2+}$ concentration. Interestingly, in breast and prostate cancer cells, PTHrP release is augmented, rather than inhibited, by activation of the $\mathrm{CaR} .{ }^{9,10} \mathrm{CaR}$ expressions are high in a lactating mother and it is due to the presence of $\mathrm{Ca}^{2+}$ in high levels $(200 \mathrm{mg}$ $\mathrm{Ca}^{2+}$ daily in lactating mothers). During lactation breast participates in $\mathrm{Ca}^{2+}$ homeostasis by monitoring $\mathrm{Ca}^{2+}$ concentrations through the $\mathrm{CaR}$ and adjusting PTHrP secretion and milk production accordingly. Elevated PTHrP release increases skeletal $\mathrm{Ca}^{2+}$ secretion and renal $\mathrm{Ca}^{2+}$ retention. The resultant increased blood $\mathrm{Ca}^{2+}$, by activating the $\mathrm{CaR}$, promotes transport of $\mathrm{Ca}^{2+}$ from blood to milk. ${ }^{11}$ There are some studies supporting dietary calcium decreases breast cancer risk. Zheng et $\mathrm{al}^{12}$ found out that the dietary $\mathrm{Ca}^{2+}$ will elevate the PTH levels in serum and it enhances bone turn over and leads to breast cancer in bones. They showed that treatment of osteoprotegerin, a naturally occurring inhibitor of osteoclast formation and activity and dietary intake of calcium in mice reduces the risk of breast cancer. Recently, it has been revealed that the change between inhibition and stimulation of PTHrP release by $\mathrm{Ca}^{2+}$ occurs as a result of a switch in $\mathrm{G}$ protein activation by the cancerous cells. Thus, in normal mammary cells, it was shown that the $\mathrm{CaR}$ couples to GI, leading to inhibition of cAMP formation and, consequently, PTHrP release, whereas in cancerous cells, (MCF7 and Comma-D cells), the CaR was shown to activate Gs, thereby promoting PTHrP release. ${ }^{13}$

In parathyroid cells, high $\mathrm{Ca}^{2+}$ levels activate the $\mathrm{CaR}$, leading to inhibition of PTH secretion, PTH gene expression, and parathyroid cell proliferation. ${ }^{14}$ It leads to the regulation of PTH synthesis and involve modulation of intracellular cAMP and $\mathrm{Ca}^{2+}$ levels as well as activation of ERK1/2 and other kinases. ${ }^{15-17}$ In parathyroid adenomas, the $\mathrm{Ca}^{2+}$ inhibits PTH secretion and it results in hyperparathyroidism and abnormal control of $\mathrm{Ca}^{2+}$ homeostasis. ${ }^{18}$

\section{1,25(OH)2D}

$1,25(\mathrm{OH}) 2 \mathrm{D}$ is very important hormone because of its protective role and is mediated by the calcium homeostasis. The major mechanism for the protective effect of vitamin D is believed to be the prostatic conversion of the vitamin $\mathrm{D}$ prohormone, 25-hydroxyvitamin $\mathrm{D}$, into the active hormone, $1,25(\mathrm{OH}) 2 \mathrm{D}$, which binds to the prostatic receptor for $1,25(\mathrm{OH}) 2 \mathrm{D}$ (the vitamin $\mathrm{D}$ receptor) and exerts prodifferentiating, antiproliferative, and antimetastatic effects on prostatic cells. ${ }^{19}$

In breast cancer cells, 1,25(OH)2D3 activates the voltage-dependent and voltage-insensitive $\mathrm{Ca}^{2+}$ entry and triggers $\mathrm{Ca}^{2+}$ release from the ER stores through the inositol 1,4,5-trisphosphate and ryanodine receptors. 1,25(OH)2D3 induces apoptosis in breast cancer cells and this apoptosis induced by $1,25(\mathrm{OH}) 2 \mathrm{D} 3$ in these cells depends on $\mathrm{Ca}^{2+}$ signaling. ${ }^{20-22} 1,25(\mathrm{OH}) 2 \mathrm{D} 3$ triggers apoptosis in breast cancer cells by causing an increase in $\mathrm{Ca}^{2+}$ entry through VICC and depletion of the ER $\mathrm{Ca}^{2+}$ stores. The resulting elevated $\left(\mathrm{Ca}^{2+}\right)$ appears to be sufficient to elicit apoptosis. ${ }^{23}$

In parathyroid adenomas $\mathrm{Ca}^{2+}$ levels and 1,25(OH)2D3 negatively regulate $\mathrm{PTH}$ synthesis and parathyroid proliferation through the activation of vitamin D receptor (VDR).

\section{Calcitonin}

Calcitonin is a hormone known to participate in calcium and phosphorus metabolism. In mammals, the major source of calcitonin is from the parafollicular or $\mathrm{C}$ cells in the thyroid gland. Calcitonin regulates the blood calcium levels. Calcitonin is used as a tumor marker for medullary thyroid cancers. Increase in ionized calcium enhances release of 
calcitonin. Clinical observations support the notion that calcitonin has little chronic effect, because neither calcitonindeficient patients (athyroid) nor patients with medullary thyroid cancer and excess calcitonin production experience alterations in calcium homeostasis. The calcitonin receptor has been cloned ${ }^{24}$ and is structurally similar to the PTH receptor in that it also has seven transmembrane domains. Calcitonin is metabolized in minutes in the circulation, predominantly in the kidney. The calcitonin receptor is related structurally to the PTH/PTH-rP and secretin receptors. The calcitonin receptor exists in several isoforms, and its expression seems to be influenced by ambient concentrations of calcitonin itself. This may be the reason for down-regulation of the receptor and the escape phenomenon that occurs in the continued presence of calcitonin. ${ }^{25}$

Recent studies have revealed that pituitary, testicular, pancreatic, and brain cancers may be influenced by the $\mathrm{CaR}$. This receptor is expressed in the human pituitary, in both normal cells and in pituitary adenomas, ${ }^{26}$ as well as in normal and malignant mouse and rat pituitary cells. ${ }^{27,28}$

\section{DISCUSSION}

Calcium $\left(\mathrm{Ca}^{2+}\right)$ is a ubiquitous intracellular signal responsible for controlling numerous cellular processes. $\mathrm{Ca}^{2+}$ signaling is used throughout the life history of an organism. Life begins with a surge of $\mathrm{Ca}^{2+}$ at fertilization and this versatile system is then used repeatedly to control many processes during development and in adult life. $\mathrm{Ca}^{2+}$ signaling toolkit emerges from the use of an extensive molecular repertoire of signaling components which makes it versatile.

One of the fascinating aspects of $\mathrm{Ca}^{2+}$ is that it plays a direct role in controlling the transcriptional events that select out the types of $\mathrm{Ca}^{2+}$ signaling systems that are expressed in specific cell types. Such a role for $\mathrm{Ca}^{2+}$ in differential gene transcription is still in its infancy but is rapidly developing into an active area of research.

$\mathrm{Ca}^{2+}$ is needed at several steps of the cell cycle, such as early $\mathrm{G}_{1}$, at the $\mathrm{G}_{1} / \mathrm{S}$, and $\mathrm{G}_{2} / \mathrm{M}$ transitions. $\mathrm{Ca}^{2+}$-mediated signaling pathways have also been shown to play important roles in carcinogenesis, such as transformation of normal cells to cancerous cells, tumor formation and growth, invasion, angiogenesis and metastasis. The transformation of a normal cell into a malignant derivative is associated with a major rearrangement of $\mathrm{Ca}^{2+}$ pumps, $\mathrm{Na} / \mathrm{Ca}$ exchangers and $\mathrm{Ca}^{2+}$ channels, which leads to enhanced proliferation and invasion under compromised/impaired ability to die.

Parathyroid hormone is the major hormone which plays a role in many endocrine cancers through altering the calcium signaling. PTH mediated cancers are regulated by the calcium homeostasis at times. It is very important to go deep into the molecular mechanism of PTH hormone actions and $\mathrm{Ca}^{2+}$ homeostasis, because it can help in the drug development and cancer treatment. The protective nature of $1,25(\mathrm{OH}) 2 \mathrm{D} 3$ is also very important in the treatment and curing of endocrine cancers. 1,25(OH)2D3 acts through the regulation of $\mathrm{PTH}$ and regulates calcium levels in blood. It has also got a major role in apoptosis in breast cancer. Calcitonin regulates the blood $\mathrm{Ca}^{2+}$ levels. In conclusion better management of the hormonal level can probably become a treatment for the endocrine cancers.

\section{REFERENCES}

1. Mukherjee S, Wesley H. Stromal interaction molecules as important therapeutic targets indiseases with dysregulated calcium flux. Brooks Department of Chemistry, University of South Florida, Tampa, FL, USA 2014 Oct;1843(10):2307-2314.

2. Arita K, Hashimoto H, Shimizu T, Nakashima K, Yamada M, Sato M. Structural basis for $\mathrm{Ca}^{2+}$-induced activation of human PAD4. Nat Struct Mol Biol 2004;11(8):777-783.

3. Mundy GR. Calcium homeostasis: hypercalcemia and hypocalcemia. 2nd ed. London: Martin Dunit 1990;1-16.

4. Ritchie CK, Thomas KG, Andrews LR, Tindall DJ, Fitzpatrick LA. Effects of the calciotrophic peptides calcitonin and parathyroid hormone on prostate cancer growth and chemotaxis. Prostate 1997;30(3):183-187.

5. Schneider A, Kalikin LM, Mattos AC, Keller ET, Allen MJ, Pienta KJ, McCauley LK. Bone turnover mediates preferential localization of prostate cancer in the skeleton. Endocrinology 2005;146(4):1727-1736.

6. Tovar Sepulveda VA, Falzon M. Hormone-related protein enhances PC-3 prostate cancer cell growth via both autocrine/paracrine and intracrine pathways. Regul Pept 2002;105(2):109-120.

7. Iwamura M, Gershagen S, Lapets O, Moynes R, Abrahamsson PA, Cockett AT, et al. Immunohistochemical localization of parathyroid hormone-related protein in prostatic intraepithelial neoplasia. Hum Pathol 1995;26(7):797-801.

8. Asadi F, Farraj M, Sharifi R, Malakouti S, Antar S, Kukreja S. Enhanced expression of parathyroid hormone-related protein in prostate cancer as compared with benign prostatic hyperplasia. Hum Pathol 1996;27(12):1319-1323.

9. Sanders JL, Chattopadhyay N, Kifor O, Yamaguchi T, Butters RR, Brown EM. Extracellular calcium-sensing receptor expression and its potential role in regulating parathyroid hormonerelated peptide secretion in human breast cancer cell lines. Endocrinology 2000;141(12):4357-4364.

10. Yano S, Macleod RJ, Chattopadhyay N, Tfelt-Hansen J, Kifor O, Butters RR, Brown EM. Calcium-sensing receptor activation stimulates parathyroid hormone-related protein secretion in prostate cancer cells: role of epidermal growth factor receptor transactivation. Bone 2004;35(3):664-672.

11. VanHouten JN, Neville MC, Wysolmerski JJ. The calciumsensing receptor regulates plasma membrane calcium adenosine triphosphatase isoform 2 activity in mammary epithelial cells: a mechanism for calcium-regulated calcium transport into milk. Endocrinology 2007;148(12):5943-5954.

12. Zheng Y, Zhou H, Modzelewski JR, Kalak R, Blair JM, Seibel MJ, Dunstan CR. Accelerated bone resorption, due to dietary calcium deficiency, promotes breast cancer tumor growth in bone. Cancer Res 2007;67(19):9542-9548.

13. Mamillapalli R, Van Houten J, Zawalich W, Wysolmerski J. Switching of G-protein usage by the calcium-sensing 
receptor reverses its effect on parathyroid hormone-related protein secretion in normal versus malignant breast cells. J Biol Chem 2008;283(36):24435-24447.

14. Brown EM, Vassilev PM, Quinn S, Hebert SC. G-proteincoupled, extracellular $\mathrm{Ca}(2)$-sensing receptor: a versatile regulator of diverse cellular functions. Vitam Horm1999;55:1-71.

15. Kifor O, MacLeod RJ, Diaz R, Bai M, Yamaguchi T, Yao T, Kifor I, Brown EM. Regulation of MAP kinase by calcium-sensing receptor in bovine parathyroid and CaR-transfected HEK293 cells. Am J Physiol Renal Physiol 2001;280(2):F291-F302.

16. Corbetta S, Lania A, Filopanti M, Vicentini L, Ballare E, Spada A. Mitogen-activated protein kinase cascade in human normal and tumoral parathyroid cells. J Clin Endocrinol Metab 2002;87(5):2201-2205.

17. MacLeod RJ, Chattopadhyay N, Brown EM. PTHrP stimulated by the calcium-sensing receptor requires MAP kinase activation. Am J Physiol Endocrinol Metab 2003;284(2):E435-E442.

18. Corbetta S, Mantovani G, Lania A, Borgato S, Vicentini L, Beretta E, Faglia G, Di Blasio AM, Spada A. Calcium-sensing receptor expression and signalling in human parathyroid adenomas and primary hyperplasia. Clin Endocrinol (Oxf) 2000;52(3):339-348.

19. Schwartz GG. Vitamin D and the epidemiology of prostate cancer. Semin Dial 2005;18:276-289.

20. Sergeev IN, Rhoten WB. Regulation of intracellular calcium in breast cancer cells. Endocrine 1998:321-327.
21. Sergeev IN, Rhoten WB, Spirichev VB. Vitamin D and intracellular calcium. Subcell Biochem 1998;30:271-297.

22. Sergeev IN. Calcium as a mediator of 1,25-dihydroxyvitamin D3-induced apoptosis. J Steroid Biochem Mol Biol 2004;8990(1-5):419-425.

23. Sergeev IN. Calcium signaling in cancer and vitamin D. Steroid Biochemistry and Molecular Biology 2005;97(1-2):145-151.

24. Lin HY, Harris TL, Flannery MS, Aruffo A, Kaji EH, Gorn A, et al. Expression cloning of an adenylate cyclase-coupled calcitonin receptor. Science 1991 Nov 15;254(5034):1022-1024.

25. Roodman GD, Takahashi S, et al. Down regulation of calcitonin receptor mRNA expression by calcitonin during human osteoclast-like cell differentiation. J Clin Investig 1995;95(1):167-171.

26. Romoli R, Lania A, Mantovani G, Corbetta S, Persani L, Spada A. Expression of calcium-sensing receptor and characterization of intracellular signaling in human pituitary adenomas. J Clin Endocrinol Metab 1999;84(8):2848-2853.

27. Emanuel RL, Adler GK, Kifor O, Quinn SJ, Fuller F, Krapcho K, Brown EM. Calcium-sensing receptor expression and regulation by extracellular calcium in the AtT-20 pituitary cell line. Mol Endocrinol Ogy 1996;10(5):555-565.

28. Ferry S, Chatel B, Dodd RH, Lair C, Gully D, Maffrand JP, Ruat M. Effects of divalent cations and of a calcimimetic on adre-nocorticotropic hormone release in pituitary tumor cells. Biochem Biophys Res Commun 1997;238(3):866-873. 